\title{
Dimensiones en la evaluación de la creatividad en campañas de comunicación integrada. Una aportación para la evaluación en el entorno docente
}

Dimensions in the evaluation of creativity in integrated communication campaigns. A contribution for assessment in the educational environmen
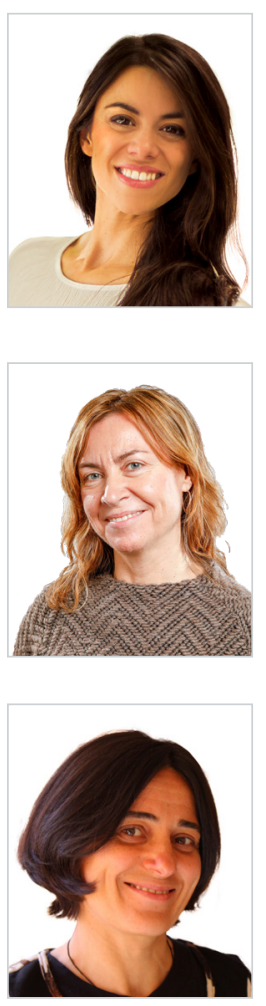

Elena González Leonardo. Profesora asociada en el Grado en Publicidad y Relaciones Públicas de la Universidad de Valladolid. Su experiencia profesional abarca diseño gráfico e industrial y creatividad en eventos y en comunicación integrada con fines sociales. Desde 2011, en paralelo a su labor profesional imparte docencia en materias relacionadas con Dirección de Arte, Identidad Visual Corporativa y Creatividad Publicitaria y en las Relaciones Públicas. Actualmente desarrolla su tesis doctoral sobre docencia de la Creatividad Publicitaria y en las Relaciones Públicas en la Universidad de Valladolid.

Universidad de Valladolid, España

elena.gonzalez.leonardo@uva.es

ORCID: 0000-0002-2350-5082

Marta Pacheco Rueda. Profesora de Teoría de la Publicidad en el Grado en Publicidad y Relaciones Públicas de la Universidad de Valladolid, España. Doctora en Ciencias de la Información por la Universidad Complutense de Madrid. Autora y coautora de diversas publicaciones sobre diferentes aspectos del fenómeno publicitario, entre sus líneas de investigación ocupa un lugar destacado el estudio de la comunicación publicitaria en el contexto digital así como la interrelación entre la publicidad y el espacio público urbano.

Universidad de Valladolid, España

martapr@ega.uva.es

ORCID: 0000-0003-0865-4212

Belinda de Frutos Torres. Profesora en la Universidad de Valladolid en el Campus de Segovia (España). Imparte docencia sobre medios publicitarios en la titulación de Publicidad y Relaciones Públicas. Doctora en Psicología por la Universidad Autónoma de Madrid. Su trabajo de investigación se ha centrado en el análisis de los medios interactivos, competencias digitales y sus implicaciones en adolescentes, en la educación y en otros ámbitos profesionales.

Universidad de Valladolid, España

belinda.defrutos@hmca.uva.es

ORCID: 0000-0002-9391-8835

Cómo citar este artículo:

González Leonardo, E.; Pacheco Rueda, M. y De Frutos Torres, B. (2020). Dimensiones en la evaluación de la creatividad en campañas de comunicación integrada. Una aportación para la evaluación en el entorno docente. Doxa Comunicación, 30, pp. 283-307.

https://doi.org/10.31921/doxacom.n30a15 
Recibido: 16/01/2020 - Aceptado: 16/04/2020

\section{Resumen:}

Evaluar la creatividad de las campañas de comunicación integrada no es tarea fácil. A pesar de que la creatividad es un aspecto de especial relevancia en el sector, la subjetividad juega un papel determinante a la hora de valorar el potencial creativo de una campaña. En el entorno profesional, los creativos establecen valoraciones subjetivas basadas en su experiencia para filtrar las distintas alternativas generadas en la agencia. En los grados en Publicidad y RR.PP. los estudiantes no poseen experiencia previa y, además, es necesario traducir dicha evaluación cualitativa a una calificación numérica que la represente. El objetivo de esta investigación es identificar las dimensiones implícitas en la evaluación de la creatividad para desarrollar un recurso que, alineado con los requerimientos de la industria, contribuya a reducir la brecha académico-profesional. El método comprende entrevistas a profesionales y una extensa revisión de la literatura. La codificación de los datos se realizó simultáneamente a la revisión bibliográfica y dio lugar a la identificación de cuatro dimensiones centrales de evaluación y 14 subdimensiones, que constituyen el modelo que se presenta que, en su aplicación en el ámbito docente, puede contribuir a evaluar y guiar el trabajo creativo de los estudiantes, así como a reforzar su dominio de la materia mediante la integración, a través de la práctica, de las dimensiones propuestas en dicho modelo.

\section{Palabras clave:}

Creatividad; evaluación; docencia; relaciones públicas; publicidad.
Received: 16/01/2020 - Accepted: 16/04/2020

\section{Abstract:}

Evaluating creativity in integrated communication campaigns is not an easy task. Despite creativity being one of the most important aspects in the sector, subjectivity plays a decisive role when evaluating creative potential in a campaign. In the professional environment, creative people make subjective evaluations based on their experience in order to screen the different alternatives produced by the agency. In the Advertising and Public Relations degrees (PR), students do not have previous experience, and as such, it is necessary to convert the qualitative evaluation mentioned into a numerical mark. The objective of this research is to identify the dimensions inherent in the evaluation of creativity in order to develop a resource in line with the requirements of the industry that might contribute to reducing the academic-professional gap. The method includes interviews with professionals and an extensive review of the literature cited. The data coding was carried out simultaneously with the bibliographic review and the result was the identification of four core evaluation dimensions and fourteen secondary that comprise the model presented, which if applied to the teaching field can contribute to evaluating and guiding students' creative work. Students can also reinforce their mastery of the subject by integrating through practice the principles proposed in this model.

\section{Keywords:}

Creativity; evaluation; higher education degrees; public relations; advertising.

\section{Introducción}

Nos hallamos inmersos en el paradigma de la Comunicación Persuasiva Integrada (CPI), caracterizado por el protagonismo del público y de un contexto que influye en emisor, mensaje y receptor al permitir la bidireccionalidad en varios canales. La integración de públicos y canales y el afán por captar la atención han diluido las fronteras que separaban comunicación, producto y entretenimiento, pasando de comunicar producto a crear productos y contenidos que comuniquen y que hagan al consumidor partícipe en la creación del valor de marca. En la búsqueda de confianza, conversación y viralidad, la CPI emplea los medios que mejor se adaptan a cada caso, maximizando las sinergias entre ellos y dando lugar a una conexión emergente entre publicidad y relaciones públicas (Castelló y Del Pino, 2019). La búsqueda de earned media y la ausencia de patrones en el empleo de los medios caracterizan las campañas de comunicación integrada, generadas a partir de un profundo conocimiento del consumidor, de sus posibles reacciones, de la sociedad y de los medios (Carretero y Rangel, 2017). Ello nos remite al término que hace ya una década acuñase el publicitario Daniel Solana en su obra Postpublicidad (2010), "creatividad líquida", en alusión a un -entonces incipiente- escenario donde el medio afecta decisivamente al mensaje y la creatividad en el uso de los medios forma parte de la propia solución creativa. 
En tal contexto, evaluar la creatividad de una campaña de comunicación integrada no es tarea fácil. A pesar de que la creatividad se considera fundamental en la industria publicitaria (Baños y Ramírez, 2004; Fallon y Senn, 2007; Navarro 2007), lo que es y no es creativo siempre estará determinado subjetivamente (Stuhlfaut y Yun, 2011). En el entorno profesional, las valoraciones recogen expresiones como "funciona", "el arte es redondo" o, en tono correctivo, "le falta un punto" o "hay que estirarlo un poco más" e, incluso, "le daría un pelín más de caña al final del copy, pero sin que se coma el claim" (Gil, 2012:155). A la hora de determinar la calidad creativa de una pieza publicitaria, la complejidad inherente a la evaluación se ve incrementada por la indefinición y la subjetividad que caracterizan las valoraciones en el sector profesional.

El número de "falla el concepto" con la certeza de que la persona que lo afirmaba y la persona que lo aceptaba estaban de acuerdo en que fallaba el concepto pero ninguna de las dos era capaz de concretarlo más, no era necesario o sencillamente no había tiempo para hacerlo. La valoración se daba por válida y acto seguido se empezaban a buscar soluciones a un problema que no se había especificado. Pasados unos días y reunidas de nuevo, se podía descubrir que aquel acuerdo era solo aparente y que cada persona interpretó de forma diferente lo que había que hacer (Gil, 2012:155).

En el sector publicitario, los creativos (directores creativos, directores de arte y redactores) establecen sus evaluaciones en función de su experiencia, que actúa como marco teórico informal (Kover, 1995) o estructura de conocimiento sistemático (Ross, 1989), y que varía en función de la persona y de la filosofía de la agencia. Este conocimiento implícito se integra de forma autodidacta a través de la práctica profesional y es difícil de transferir entre individuos, por lo que es de esperar que las dimensiones implícitas en la evaluación varíen dependiendo de quién la realiza y del contexto donde se llevan a cabo. Durante el proceso creativo, las distintas propuestas que surgen en la agencia siguen una serie de filtros que determinan, por un lado, qué alternativa será la que se lance al público y, por otro, qué camino ha de seguir la materialización de la idea. En publicidad, el primer filtro para juzgar las alternativas creativas lo realizan las duplas o equipos de arte y copy durante la ideación (Stuhlfaut, 2011); a continuación, las propuestas generadas son valoradas por la dirección creativa y otros profesionales de la agencia para seleccionar qué propuesta se presentará para ser aprobada por el anunciante y, en última instancia, por el público. No será hasta analizar las respuestas de este último, tras el lanzamiento de la campaña, cuando agencia y anunciante comprobarán si su apuesta ha cumplido las expectativas estimadas.

En el entorno docente y, en concreto, en las asignaturas relacionadas con creatividad publicitaria y en las relaciones públicas (RR.PP.) enmarcadas en los grados en Publicidad y RR.PP. españoles, por lo general se trata de emular en el aula la actividad de las agencias de publicidad. En el marco docente, es habitual que las primeras evaluaciones tengan lugar en los equipos de trabajo formados por los estudiantes y que el rol de dirección sea asumido por el profesor, quien ofrecerá feedback a los estudiantes sobre las propuestas planteadas. Normalmente, la evaluación de la capacitación del alumnado se realiza a través de su producto creativo (campañas de comunicación integrada o piezas creativas de distinta índole) que, en la mayoría de los casos, no llega a lanzarse al público, de forma que la evaluación de la calidad creativa finaliza en la estimación de un potencial creativo bajo el que subyace una ficticia previsión de resultados. En ocasiones se llevan a cabo metodologías docentes o proyectos que implican al sector profesional en el propio desarrollo académico de las campañas creativas, como es el caso de la iniciativa interdisciplinar "Emprendedores y Creativos", desarrollada en la Universidad CEU San Pablo, que pone en perspectiva la integración de los conocimientos disciplinares y la implicación de la industria en la formación del alumno, a través del contacto con clientes y profesionales en el proceso y en la evaluación 
de las campañas de comunicación desarrolladas por los estudiantes (Bartolomé, Viñarás, y Llorente, 2012; Bartolomé, Llorente, y Marugán, 2018).

En ambos contextos la subjetividad está presente en la evaluación, pero las implicaciones derivadas de la ausencia de sistematización son muy distintas. En el sector profesional, la subjetividad y la intuición están avaladas por la experiencia. Sin embargo, en el entorno docente, los estudiantes carecen de experiencia y, además, es necesario traducir la evaluación cualitativa a una calificación numérica que la represente y que sea comprendida por aquellos. La ausencia de referencias en torno a las dimensiones que determinan la calidad creativa de una campaña de comunicación integrada incrementa la dificultad de convertir la evaluación docente en un aspecto comprensible y formativo. Puede darse el caso de que la persona encargada de la docencia reconozca de alguna forma sus rutinas profesionales y sea capaz de trasladarlas y exponerlas en el aula (Gil, 2012), aplicando así, fruto de su experiencia, su propia sistematización intuitiva. Sin embargo, esto no garantizaría un criterio coincidente entre facultades, ni siquiera entre asignaturas, debido, precisamente, a dicha subjetividad. Por su parte, los estudiantes necesitan recursos que contribuyan a entrenar el juicio crítico y a objetivar, en cierta medida, el filtro sobre sus propias creaciones, así como detectar y comprender las debilidades o fortalezas de sus propuestas para subsanar errores o potenciar oportunidades. Las características de los grupos -habitualmente numerosos y heterogéneos, ya que los estudiantes poseen expectativas y habilidades diversas en torno a la creatividad (Gil, 2012)- incrementan la necesidad de que los equipos sean capaces de guiar su trabajo para avanzar, realizar filtros de primer nivel e intercambiar feedback con cierta autonomía. Para que esto sea posible, los estudiantes necesitarán adquirir unas competencias mínimas sobre la materia, que podrían traducirse en un dominio mínimo de las dimensiones que determinan la calidad creativa.

La mayoría de estudios sobre las necesidades del sector académico señalan la existencia de una brecha entre la capacitación de los estudiantes y las necesidades reales de la profesión. Corredor y Farfán (2010:111) afirman que "la enseñanza reglada en Publicidad y RR.PP. no aprueba la evaluación del sector profesional” considerando, en línea con lo propuesto por la mayor parte de las investigaciones sobre las necesidades del sector, que lo que debe cambiar es la capacitación de los discentes para promover su integración a los requerimientos de la industria (Cook, 2002; Altarriba y Rom, 2008; Corredor y Farfán, 2010). Sin embargo, el momento que vive la industria de la comunicación hace que sea aún más complicado categorizar las dimensiones en base a las que debemos evaluar y formar a los estudiantes.

A pesar de la centralidad de la consideración de la creatividad en publicidad, es llamativa la exigüidad de la investigación científica sobre la evaluación de la creatividad, quizá por la dificultad que entraña la definición del término creatividad, por la propia naturaleza del proceso creativo, por la diversidad de los productos creativos o por el complejo entorno que rodea la creatividad publicitaria (Klebba y Tierney, 2012). Aún más reducida en tamaño y alcance es la investigación sobre la creatividad en RR.PP., que solo recoge el creciente protagonismo que está adquiriendo en el sector y, en relación a ello, los cambios necesarios en torno al proceso creativo y a la necesidad de transformación de algunos perfiles (The Holmes Report, 2013; Estanyol y Roca, 2014). Del análisis de Estanyol y Roca (2014) se desprende que, a pesar de que la creatividad en RR.PP. es cada vez más valorada en el sector y más demandada por los clientes, aún está lejos de obtener el reconocimiento y la importancia de los que goza en la industria publicitaria. Por este motivo, y dada la ausencia de investigaciones académicas en torno a la evaluación de la creatividad en RR.PP., se aborda la investigación empírica desde la perspectiva publicitaria. 


\section{Objetivos}

El objetivo de esta investigación es identificar las dimensiones que subyacen a la evaluación de la creatividad de campañas de comunicación integrada con el propósito final de desarrollar un recurso que permita a los alumnos de grado en Publicidad y RR.PP. asimilar criterios que contribuyan a valorar la creatividad de sus propuestas de comunicación.

El trabajo se centra en dar respuesta a la siguiente pregunta de investigación: ¿Qué dimensiones definen la calidad creativa de una campaña integrada de comunicación? Para responder a esta cuestión se recurre a las entrevistas en profundidad de una muestra de profesionales de la comunicación que ejercen su actividad dentro del área de la creatividad. Las dimensiones implícitas identificadas en la evaluación profesional se ponen en perspectiva respecto a las dimensiones de evaluación de la creatividad propuestas desde la investigación académica. Como resultado de esta integración, se propone un modelo de evaluación de la creatividad para campañas de comunicación integrada.

\section{Metodología}

\subsection{Método}

Para la identificación de las dimensiones de evaluación, el estudio se basa en el método de la Teoría Fundamentada donde el investigador "recoge, codifica y analiza datos en forma simultánea" (Soneira 2006:155). La investigación no se inicia a partir de supuestos a priori o marcos teóricos existentes; las hipótesis emergen de los datos y las aportaciones de la revisión bibliográfica son incorporadas durante el proceso de análisis para complementar la información extraída. Los conceptos y sus relaciones son examinados de forma continua y sistemática hasta lograr la saturación de los datos. La revisión de la literatura se realiza en paralelo a la categorización de las dimensiones de evaluación y al diseño del modelo.

Los datos son extraídos a partir de entrevistas a directores creativos de varias agencias de publicidad y de una extensa revisión documental categorizada en tres tipos de recursos: (1) investigaciones sobre las dimensiones de evaluación de la creatividad, (2) investigaciones sobre evaluación de la creatividad en publicidad y (3) modelos predecesores en la evaluación de la creatividad publicitaria diseñados para su aplicación en el entorno profesional.

\subsection{Muestra}

La selección de los entrevistados se realiza conforme a los siguientes criterios: (1) haber trabajado en el departamento creativo de alguna agencia de publicidad multinacional, (2) tener más de 7 años de experiencia en publicidad y (3) haber participado en festivales de publicidad, bien por haber sido jurado o premiado.

El procedimiento para definir el tamaño final de la muestra es controlado por la teoría emergente (Glaser, 1978) y consiste en identificar las dimensiones de evaluación durante las entrevistas hasta lograr su saturación mediante el análisis comparativo constante (Glaser, 1992). Durante las primeras entrevistas se identifica qué información es necesario ampliar o en qué aspectos debemos incidir (Glaser y Strauss, 1967), siendo esta información relevante para la adaptación formal de las entrevistas restantes. La determinación del tamaño de la muestra se realiza conforme a las indicaciones de San 
Martín (2014:113): "en el instante en que las comparaciones constantes entre los datos no evidencian nuevas relaciones o propiedades de los datos se evidencia la saturación teórica y no es conveniente realizar más entrevistas y observaciones"; tras 5 entrevistas los datos comienzan a tornarse repetitivos y al cabo de 9 dejan de aparecer datos nuevos, por lo que finalizamos la fase de entrevistas y recogida de información. En la tabla 1 se recogen las características de cada entrevistado.

Tabla 1. Características de los entrevistados

\begin{tabular}{|c|c|c|c|c|c|}
\hline $\begin{array}{c}\text { Entrevistado } \\
n^{\circ}\end{array}$ & Perfil profesional & $\begin{array}{l}\text { Multinacional donde ha } \\
\text { desarrollado la mayor parte } \\
\text { de su carrera. } \\
\text { / Última agencia donde ha } \\
\text { trabajado. }\end{array}$ & $\begin{array}{c}\text { Experiencia } \\
\text { profesional (años) }\end{array}$ & $\begin{array}{c}\text { Experiencia } \\
\text { como jurado } \\
\text { en festivales de } \\
\text { publicidad }\end{array}$ & Género \\
\hline E1 & Director creativo ejecutivo & JWT / Neolabels & Cerca de 20 años & sí & M \\
\hline E2 & Director creativo ejecutivo & $\begin{array}{l}\text { GREY / Pingüino } \\
\text { Torreblanca }\end{array}$ & Más de 20 años & sí & $\mathrm{H}$ \\
\hline E3 & Director creativo ejecutivo & Proximity & Cerca de 20 años & sí & M \\
\hline $\mathrm{E} 4$ & Director creativo / Copy & Proximity & Más de 20 años & sí & $\mathrm{H}$ \\
\hline E5 & Director creativo / Arte & BBDO / Proximity & Más de 10 años & sí & M \\
\hline E6 & Director de arte & Shakleton & Cerca de 10 años & no & $\mathrm{H}$ \\
\hline E7 & Director creativo / Copy & BBDO / Ele\&Uve & Más de 10 años & no & M \\
\hline E8 & Director creativo / Arte & BBDO / Ele\&Uve & Más de 10 años & no & M \\
\hline E9 & Director creativo / Arte & SCPF / PS21 & Más de 10 años & sí & M \\
\hline
\end{tabular}

Fuente: Elaboración propia

En lo que respecta a la variabilidad de agencia y de holdings internacionales, los sujetos E1, E2 y E9 han trabajado en agencias pertenecientes a WPP (Grey, SCPF, JWT); los sujetos E3, E4, E5, E7 y E8 han trabajado en agencias pertenecientes a Omnicom Group (BBDO, Proximity) y el sujeto E6 ha trabajado en agencias pertenecientes a Publicis Worlwide (Leo Burnett). Además, los sujetos: E1, E2, E6, E7 y E8 han dirigido o trabajado en agencias independientes, lo que consideramos que complementa su perspectiva y enriquece el estudio.

\subsection{Procedimiento}

En primer lugar, se realizan las entrevistas usando una adaptación de la guía de entrevistas propuesta por Kover (1995). Las entrevistas son de tipo semiestructurado para ofrecer mayor libertad de desarrollo a los participantes. Para evitar coartar o dirigir las respuestas, el propósito concreto de la investigación no se revela a los entrevistados. Se inician las conversaciones con una batería de preguntas sobre la formación y experiencia profesional de los participantes, lo que aporta información relevante para la interpretación de los datos y genera un clima de confianza previo. Las entrevistas se estruc- 
turan en dos partes: la primera comprende preguntas de tipo general para introducir al entrevistado en la temática y, en la segunda, el núcleo lo constituyen preguntas relacionadas con la información más relevante para el estudio. Como cierre, se incorporan preguntas abiertas para dar la oportunidad a los entrevistados de realizar aportaciones espontáneas ${ }^{1}$.

Las entrevistas se realizan por teléfono y son grabadas y posteriormente transcritas. En el transcurso de las conversaciones se toman notas y se recogen los aspectos de la evaluación que cada entrevistado destaca como importantes. La codificación, de tipo abierto y axial, se realiza simultáneamente a la recopilación de datos. Durante la codificación abierta se identifican, nombran y categorizan los conceptos descubiertos en el texto transcrito. Tales conceptos (o subdimensiones) son clasificados y, posteriormente, agrupados en conjuntos homogéneos que contribuyen a identificar varias dimensiones centrales y, a su vez, aportan valor explicativo a las mismas. Se consideran como dimensión las respuestas o significados repetidos, equivalentes a una estructura de conocimiento descriptiva de la calidad creativa de una campaña de comunicación. Durante la codificación axial, los códigos (dimensiones y subdimensiones) se relacionan entre sí mediante una combinación de pensamiento inductivo y deductivo que contribuye a la construcción del modelo. La categorización es de tipo conceptual, es decir, de ideas y no de datos, para prevenir la regresión hacia informes puramente descriptivos. De acuerdo con el método, los datos no se codifican para encajar en teorías o construcciones preexistentes sino centrando la atención en las conceptualizaciones subyacentes. El umbral para clasificar las dimensiones y subdimensiones es haber sido mencionado por el $80 \%$ o más de los entrevistados.

En línea con lo propuesto por Glaser (1978), la literatura académica es revisada durante el proceso de análisis contribuyendo a descubrir nuevas propiedades de las dimensiones y subdimensiones, así como de sus relaciones. La investigación académica relevante es clasificada para complementar las categorías y conceptos extraídos, dando lugar a los contenidos del modelo emergente.

\section{Resultados}

\subsection{Dimensiones para evaluar la creatividad desde el ámbito profesional}

Siguiendo el procedimiento descrito, los conceptos emergentes del discurso de los profesionales dan lugar a varias categorías generales que son desglosadas en subparámetros y revisadas hasta ser reducidas a cuatro dimensiones que se contrastan nuevamente con la revisión de la literatura académica: originalidad, eficacia, engagement y ejecución. Sumado a ello y en línea con los hallazgos de Stuhlfaut y Yun (2011), el 55,5\% de los entrevistados destaca también la fuerza de los insights sociales o la adecuación al momento o al contexto como un punto fuerte en la búsqueda de impacto y notoriedad de la campaña. La tabla 2 recoge las dimensiones de evaluación de la creatividad extraídas en las entrevistas.

$1 \quad$ La guía de conducción de la entrevista puede consultarse en el anexo de este artículo. 
Tabla 2. Dimensiones y subdimensiones de evaluación de la creatividad extraídas de las entrevistas

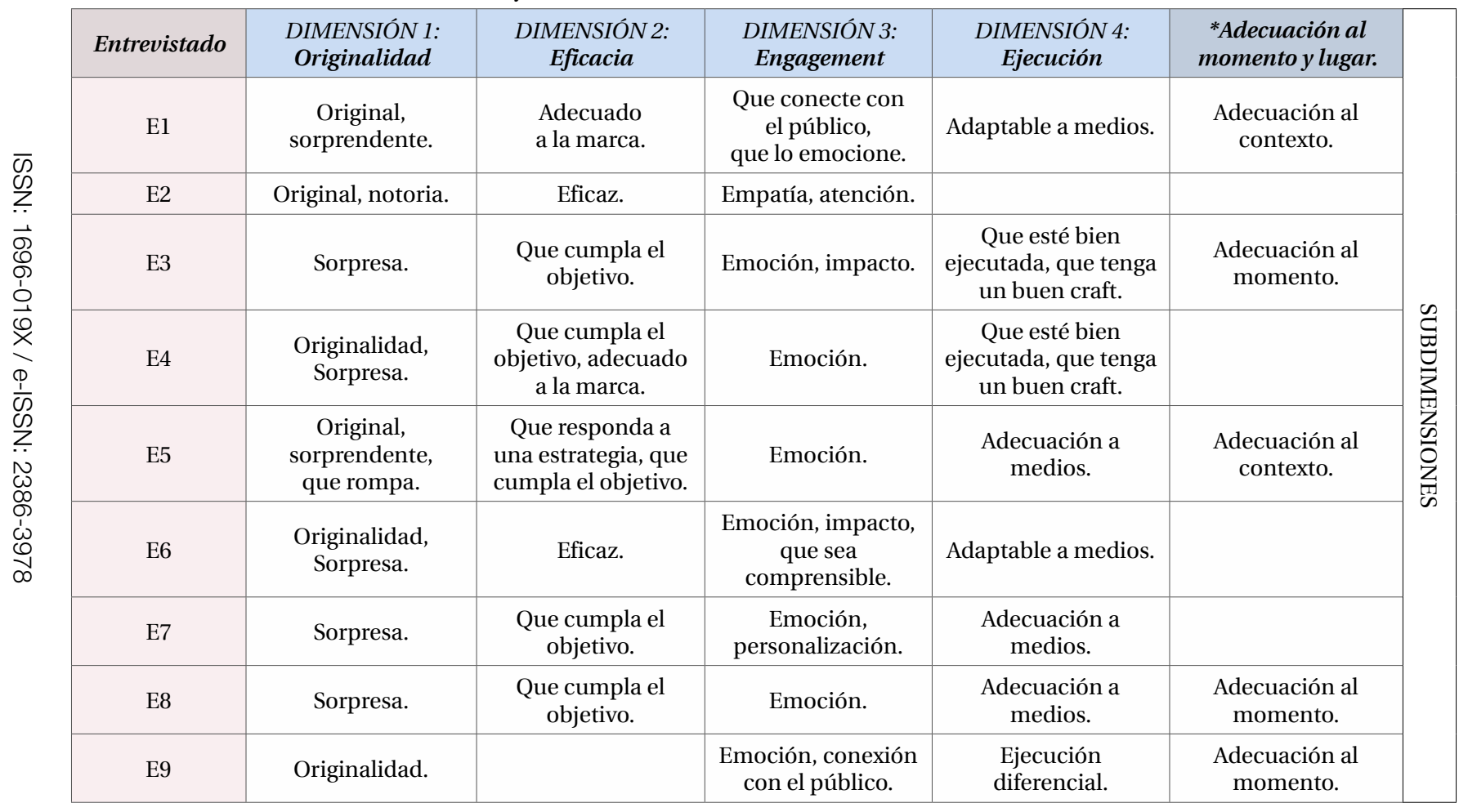

Fuente: Elaboración propia

\subsection{Dimensiones de la evaluación de la creatividad desde la investigación académica}

De forma paralela a la identificación de las dimensiones implícitas en la evaluación profesional, revisamos la literatura académica para complementar la teoría emergente. Comprobamos que los intentos de definir la evaluación de la creatividad han variado en sus características, en el número y en la definición de sus dimensiones. Desde la psicología, numerosos autores han definido la creatividad como aquella novedad que supone utilidad (Treffinger, 1980; Amabile, 1983; Besemer y O'Quinn, 1989; Runco y Charles, 1993; Plucker y Beghetto, 2004; Jackson, 2005). No obstante, la originalidad y la utilidad no son suficientes para evaluar la creatividad aplicada. De ahí que la mayoría de los trabajos sobre evaluación de productos creativos en publicidad establezcan criterios múltiples, argumentando que se trata de un fenómeno de carácter multidimensional. Estudiamos las dimensiones de evaluación propuestas por varios autores, que han abordado la evaluación de la creatividad desde la psicología y la publicidad, en relación a las cuatro dimensiones de nuestra teoría fundamentada. La tabla 3 sintetiza los ítems de evaluación propuestos en cada caso: 
Tabla 3. Dimensiones y subdimensiones de evaluación de la creatividad procedentes de la investigación académica

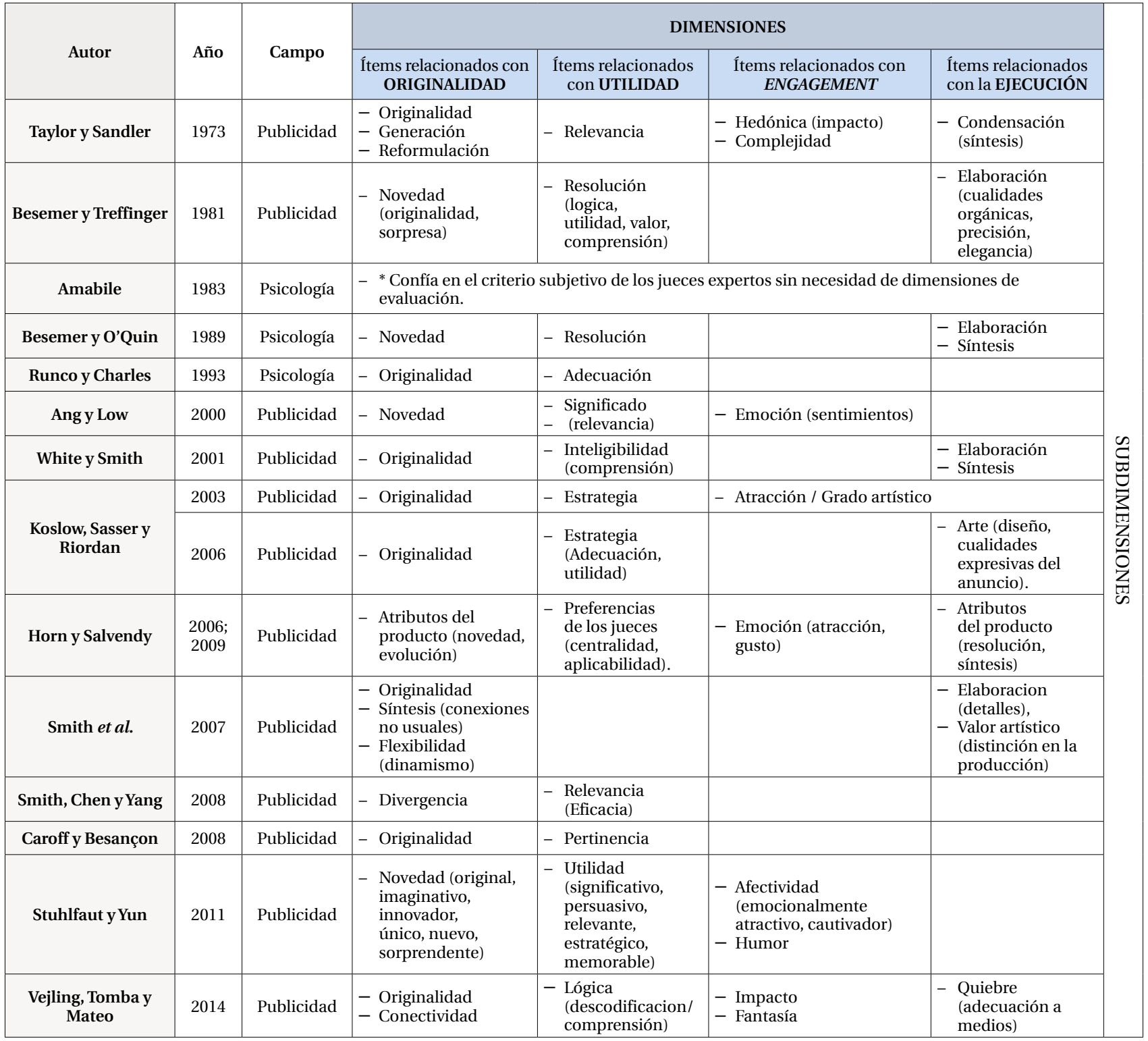


Observamos que, bajo distintos conceptos o subparámetros (novedad, conectividad, innovación, sorpresa, divergencia o flexibilidad), todos los autores reflejan la originalidad como dimensión de evaluación. Otra dimensión común es la eficacia, igualmente contemplada desde distintas perspectivas (relevancia, utilidad, pertinencia, estrategia, adecuación, comprensión o memorabilidad). Aunque el modelo propuesto por Smith et al. en 2007 no recoge la eficacia, el estudio realizado por Smith, Chen y Yang en 2008 es una evolución del anterior y plantea únicamente dos dimensiones, divergencia y relevancia, por lo que se puede afirmar que la totalidad de los autores estudiados reflejan la eficacia como dimensión.

En lo que respecta al engagement, los modelos más recientes (Sthufault y Jun, 2011; Vejling, Tomba y Mateo, 2014) proponen la afectividad, el humor, el impacto o la fantasía (imaginación), como recursos para conectar con el consumidor. Sin embargo, los modelos anteriores apenas contemplan esta dimensión y, si lo hacen, la expresan bajo un solo subparámetro (impacto, emoción o atracción). Es de esperar que los últimos modelos, enmarcados en la era de la comunicación persuasiva integrada, sí contemplen dimensiones para medir la conexión con el consumidor. De igual modo que, desde el punto de vista de la ejecución, el modelo más reciente (Vejling, Tomba y Mateo, 2014) propone como dimensión la adecuación a medios (quiebre), difiriendo de los modelos anteriores, que recogen la ejecución únicamente desde un enfoque formal (valor artístico, resolución o síntesis).

Otro factor, detectado a partir de las entrevistas y de la revisión de la literatura, y que influye sobre la determinación de las dimensiones, es la diferencia de juicio en los distintos contextos del sector profesional donde se ejecuta la evaluación: festivales, agencia y cliente. Dado que los festivales premian "la mejor" publicidad del año, cabría esperar que los procesos de selección respondieran a un criterio riguroso que actuase como referente para el presente estudio. Sin embargo, esta expectativa no se cumple en la realidad ya que, lejos de seguir una calificación sistemática que responda a unas dimensiones ponderadas, los premios se otorgan sobre una valoración global que es fruto de la subjetividad de los miembros del jurado. Entre las directrices otorgadas por el festival prima la dualidad originalidad-eficacia, pero la relevancia de cada dimensión varía según el festival ${ }^{2}$ (Aguilera, 2017). West, Caruana y Leelapanyalert (2013) determinan una tercera dimensión, la ejecución, que se integra en varios festivales y/o categorías bajo distintas ponderaciones. No obstante, todos los entrevistados coinciden en que las directrices que marcan la evaluación no son las "oficiales", que se recogen en la página web de cada festival, sino los criterios marcados por los presidentes de las distintas mesas.

En los festivales suele haber un presidente que es quien suele marcar las guide-lines de lo que está buscando el festival. A la hora de juzgar las piezas... tienes más o menos esa directriz. Por ejemplo en Cannes, suelen ser ideas súper revolucionarias que cambien el mundo a mejor, ya sabes que las ideas tienen que cumplir más o menos ese criterio...o si es un festival como el Inspirational, que busca ideas innovadoras e inspiradoras, pues tienes que orientar lo que estás buscando un poco a eso... También tiene que ir acompañada [la idea] de la ejecución. (E2)

Varios entrevistados se muestran críticos con la evaluación de la creatividad en los festivales, pues consideran que actúan como plataforma promocional para las agencias y el propio sector y poseen un afán recaudatorio que influye en su operativa. Y denuncian que muchas campañas nunca llegan al público, que son creadas "por publicistas para publicistas"

2 Festivales como Cannes Lions, El Sol, Clio Award, C de C... están más centrados en la originalidad mientras que los Effie Awards, IPA Effectiveness Awards o los premios concedidos por la APG, son los certámenes que más valoran la eficacia (Aguilera, 2017). 
(E6). Las dimensiones y subdimensiones de evaluación creativa ofrecidas por los entrevistados (Tabla 1) se refieren a los parámetros que rigen el trabajo creativo en su día a día, es decir, a lo que determina una buena campaña desde el punto de vista de la agencia y del cliente. Es por ello que, si nos alejamos de los festivales para pasar a valorar lo que sería una buena campaña para la agencia o para el cliente, vuelve a coger fuerza el concepto de utilidad o eficacia.

\subsection{Modelo para la evaluación de la creatividad de campañas de comunicación integrada}

A medida que se identifican las dimensiones y subdimensiones de evaluación en los ámbitos académico y profesional, surge la necesidad de valorar las distintas interpretaciones asociadas a los conceptos emergentes, para lo cual se analizan en profundidad las definiciones que de los mismos aportan profesionales e investigadores. La variedad de enfoques contribuye a considerar distintas posibilidades en el planteamiento y organización de las relaciones y jerarquías de las dimensiones y subdimensiones encontradas. Los resultados obtenidos están organizados en cuatro dimensiones de evaluación de la creatividad (originalidad, eficacia, engagement y ejecución) y 14 subdimensiones vinculadas a las mismas:

\subsubsection{Originalidad}

La mayoría de autores coinciden en que la idea creativa debe ser original (Hernández, 2004; Burtenshaw, Mahon y Barfoot, 2007). Sin embargo, el concepto ha sido definido e interpretado de diversas maneras. Así, Ricarte (1999) y Arroyo (2006) se refieren a originalidad como novedad. Sarkar y Chakrabarti (2011) afirman que una manera de determinar lo novedoso de un producto es comparar las características de dicho producto con las de otros, disponibles en el momento de su introducción y que están destinados a satisfacer la misma necesidad. Por su parte, Vejling, Tomba y Mateo (2014) definen la originalidad como "la rareza relativa de algo, que lo hace diferenciarse de lo esperado por el público" y, en su modelo, recogen también una dimensión denominada "conectividad", entendida como unión entre pensamientos que en apariencia no tenían vinculación y que es responsable de causar sorpresa. Torrance (1977) y Guilford (1950) también destacan el establecimiento de conexiones como una forma de novedad. En línea con ello, algunos entrevistados definen la originalidad como "agilidad para conectar ideas" (E5) y la mayoría de ellos (6 de 9) relacionan el establecimiento de conexiones con la originalidad y refieren la observación constante como fuente de inspiración para la misma.

En cuanto a la relación de la originalidad con la sorpresa, Ricarte (1999) afirma que la creatividad tiene como misión "hacer sorprendente lo evidente". La sorpresa motiva a los individuos a resolver lo inesperado, aumentando su esfuerzo y atención. Taylor, Wilson, y Miracle (1994) descubrieron que cuando las campañas contenían un mensaje diferente al esperado había actitudes más favorables hacia la campaña y la marca, y una mayor atención de compra en comparación con los anuncios que poseían mensajes no diferenciadores. Twose y Polly (2011) profundizaron en ello al contrastar la relación entre respuestas psicológicas y ventas a través del análisis de campañas que obtuvieron premios de eficacia (IPA) o de creatividad (Cannes). El listado de emociones era muy amplio, pero solo una de las emociones, el sentimiento de sorpresa, correlacionaba con la eficacia vendedora o creativa. La medición del valor persuasivo correlacionaba con un ligero salto en las ventas aunque, generalmente, no constituía aportación al valor de marca, que es el garante del largo plazo.

Ligado también al concepto de originalidad se identifica el de innovación, entendida como aportación que supone novedad. Varios festivales introducen entre sus criterios la innovación (Barahona, 2019), entendiendo por ésta que la campaña 
suponga una aportación al sector. Conectada con ella se encuentra el criterio de inspiración, que valora el hecho de que una campaña o pieza se convierta en tendencia social, llegando a ser prescriptora dentro del sector. Obradors (2007) atribuye un nuevo epíteto a la publicidad que posee un gran nivel de innovación, denominándola "blindada", ya que se convierte en única y alcanza el grado máximo de originalidad.

De acuerdo con este enfoque, se induce que la capacidad para conectar ideas de forma innovadora o inesperada es una forma de conseguir originalidad. De este modo, la primera dimensión implícita en la evaluación de campañas de comunicación integrada es la originalidad, definida como empleo de recursos bajo un prisma innovador y no predecible, y se encuentra vinculada a los subparámetros (1) conectividad, (2) factor sorpresa e (3) innovación.

\subsubsection{Eficacia}

David Ogilvy y Bill Bernbach revolucionaron el mundo de la mercadotecnia y la comunicación demostrando que también con creatividad podía conseguirse lo que pedía el cliente (Fallon y Senn, 2007: 18). Autores como Bassat (1993), Ricarte (1999) y Hernández (2004) apoyan la idea de que la creatividad publicitaria debe siempre cumplir los objetivos, ya sean estos en términos de ventas o de imagen. Burtenshaw, Mahon y Barfoot (2007) alertan del peligro de dejarse llevar por una idea creativa hasta olvidarse del objetivo principal del briefing, de las necesidades del target o incluso descuidar la visión global del problema. Los entrevistados destacan la eficacia como un componente imprescindible en una buena campaña.

Para mí, una buena campaña de publicidad es una campaña que soluciona un problema de negocio del cliente. Stop. Después de muchos años de experiencia creo que estamos en un negocio donde hay unos objetivos y si el de nuestro cliente es vender o alcanzar unos niveles de notoriedad, una buena campaña tiene que construir eso. (E3)

Tu cliente te pide una campaña para cubrir un objetivo; por muy original que sea, si no has cumplido el objetivo del briefing, no sirve. (E7)

Una campaña buena es la que vende. Somos comunicadores pero somos vendedores. Nuestro objetivo es vender productos y a veces vender ideas, marcas... La campaña buena es la que funciona, y lo que ahora está cogiendo mucha relevancia son los premios a la eficacia. Me parece muy justo, porque hay muchos festivales en los que se premia la idea, la creatividad, pero todo esto está hecho para que funcione. Para mí la campaña que vende es la mejor, lo que pasa es que yo le exijo a la campaña que venda, que además sea creativa, que sea diferente, notoria. Una campaña tiene que tener esos ingredientes que llamen la atención y generen empatía. (E2)

Bassat (1993) habla de creatividad publicitaria como la traducción a una pieza de toda la investigación y la estrategia. La investigación es crucial en las campañas de comunicación integrada, ya que solo con un conocimiento exhaustivo de los consumidores, de la marca y del contexto, se pueden alcanzar los objetivos de ventas y de comunicación (Halper, 2013). No obstante, la investigación es una fuente de inspiración para la estrategia creativa pero, en ningún caso, el trabajo de los creativos debe supeditarse a comunicar de la forma más creativa posible sus conclusiones. De lo contrario, la espontaneidad se vería limitada y la investigación supondría un lastre en lugar de un recurso estratégico.

La eficacia representa la segunda dimensión implícita en la evaluación, expresada en términos de estrategia, y desglosada en 4 subparámetros que indican su gradación o logro: (1) cumplimiento de objetivos, (2) adecuación a la marca, (3) adecuación al contexto y (4) adecuación al target. 


\subsubsection{Engagement}

En el contexto actual adquiere especial relevancia la capacidad para generar engagement. Solana (2010:11) reafirma la teoría de Goldhaber (1997) afirmando que "vivimos en una economía donde el bien escaso por excelencia es la atención del público" y valora que "en ese contexto, el escenario globalizado, holístico, de contenidos revueltos, en el que la atención es tan escasa, los publicitarios nos convertimos en mendigos de la atención” (2010: 35). Es aquí donde la publicidad se fusiona con los contenidos para lograr un entretenimiento o utilidad que se aleje de lo intrusivo.

Hay que tener en cuenta que el espectador no nos está esperando, no nos está mirando, e incluso cuando está prestando la atención que nos gustaría que prestase a lo que decimos, hay que encontrar la manera de captar, la manera de empatizar y de no "molestar mucho" a la gente. Siempre fue una de esas primeras cosas que nos contaban en publicidad: que normalmente interrumpimos la vida cotidiana de la gente con nuestros mensajes y solo tenemos dos alternativas: o le contamos a la gente algo que diga "me ha merecido la pena realmente escuchar algo porque es una oferta muy buena", o es algo que no sabía, o entretener... Una campaña tiene que tener esos ingredientes que llamen esa atención y generen esa empatía. (E2)

Los consumidores lo que quieren es entretenimiento, que les haga pasar un buen rato, que les impactes, que les sorprendas, no buscan que les den información racional y práctica acerca del producto, buscan algo más emocional. (E3)

Vejling, Tomba y Mateo (2014) hablan de una dimensión denominada "emotividad", planteada como "anzuelo sensitivo" que permita identificar el grado de emoción provocada en el target. Por su parte, los entrevistados se refieren a la emoción indicando que cuando una idea es buena, enseguida "se nota" (E5) y produce esa "sensación en el estómago" al verla (E4, E6, E8). El neuromarketing y las teorías sociológicas de la jerarquía de efectos ponen de manifiesto la influencia de la afectividad y la emoción en la percepción de los impactos y en la toma de decisiones posterior (López de Ayala, 2004).

Para lograr "enganchar" al consumidor, el valor que se le ofrece al usuario debe estar bien definido y el acceso a la experiencia debe ser inmediato, fácil, cómodo y lúdico. Gran parte de los recursos para conectar con el espectador tienen su origen en el medio, en la personalización y en la incorporación de estos datos de contexto que permiten que el usuario se sienta interpelado. El reto y el riesgo residen en no emplear informaciones tan personales que deriven en una sensación de pérdida de privacidad (Tucker, 2014). El modelo de comunicación se ha personalizado y el estudio del target ha evolucionado hacia el estudio de los buyer persona en torno a los distintos segmentos del público con el fin de crear comunicaciones más acordes con sus estilos de vida.

[...] para mi también está la personalización, ahora, para que una campaña sea una buena campaña, creo que tiene que estar muy targetizada, creo que las campañas que quieren ir a hombres y mujeres de todos los estratos sociales, ya no valen. Que las que van al estrato social que tienen que ir, son las que tienen impulso. (E7)

Antes [llegar de forma tan segmentada] era imposible pero ahora, con el big data, se puede hacer. Podemos ir a mujeres con estudios primarios que vivan en un ambiente rural y que tengan menos de 25 años, se puede. (E8)

Hubbard (2018), partiendo del desorden generado por la sobreexposición y la emergencia de canales y medios (a la que se refiere bajo el término "clutter") destaca la importancia del "gancho" ("hook"), interpretado como la forma en que se elabora el mensaje y como atracción detonada mediante la descodificación. Vejling, Tomba y Mateo (2014) denominan "lógica" a la forma de presentar el contenido al perceptor para que este pueda descodificarlo. Bassat (1993) y Hernández 
(2004) manejan este concepto en términos de simplicidad, entendida como claridad y sencillez en la transmisión del mensaje para facilitar la conexión con el destinatario. Al consumidor le gusta que la creatividad apele a su inteligencia pero no le gusta que le obligue a estudiarse los anuncios hasta comprenderlos (Navarro, 2007).

En conexión con lo expuesto, el concepto paraguas elegido para aglutinar los ítems que abarcan la conexión con el consumidor es el término engagement, entendido como la capacidad de "enganchar" al consumidor o el grado en el que un consumidor interactúa con una marca. Podría decirse que el engagement evidencia el compromiso entre la marca y los usuarios, que representa el "vínculo entre una serie de comportamientos del cliente hacia la empresa que van más allá de la acción de compra y que se producen como resultado de motivaciones individuales" (Van Doorn et al., 2010). Los subparámetros vinculados al engagement son (1) el impacto, (2) la empatía y (3) la emoción.

\subsubsection{Ejecución}

Carretero y Rangel (2017) afirman que la adaptación de los medios al mensaje es una característica representativa de las campañas de comunicación integrada: todo cabe en estas campañas: un documental, una canción (no entendida como jingle de campaña, sino como campaña en sí misma), un producto a vender, un software, un simple tweet o un experimento sociológico. El mensaje no llega de forma intrusiva sino que se convierte en parte de la vida de la gente, entretiene e incluso da motivos para tomar una posición vital. El impacto no es tan importante como la experiencia pues, si ésta es gratificante para el consumidor, se convertirá en el altavoz de la empresa y en su medio ganado. Los entrevistados coinciden en que el éxito de la campaña proviene de la combinación de ideas nuevas y antiguas, que la forma de idear la publicidad no cambia, ya que el concepto siempre tiene que primar y ser declinable en todas las plataformas.

Hay ideas que "tiran" de insights básicos pero que no valen tal y como se han hecho hasta ahora, hay que transformarlas con lo que se puede hacer ahora. Pero las ideas puras conceptualmente son igual de válidas ahora que antes, aunque es cierto que la idea ya está más condicionada al medio. No es lo mismo hacer una campaña de TV y ahora una versión para Stories, porque no va a funcional igual, tienes que saber cómo funciona Stories, cómo funciona el medio, y a partir de ahí hacer la campaña. Pero no pueden ser ya adaptaciones de la idea primigenia, cada uno tiene que "bajar" de una forma, condicionado por el medio en el que estás. (E7)

Adaptar la idea a todos los canales es fundamental, eso de repetir el anuncio del banner, no. (E1)

Una buena idea tiene que ser ejecutable en muchos soportes, porque si solo sirve para una parte de lo que puedes abarcar, tienes que ir al origen para luego segmentarla bien. Hay muchas ideas que dices... joder!, me he inventado una cosa que funciona muy bien en Spotify, pero solo sirve para Spotify. Hay ideas que son así, pero si hablamos de una idea grande, lo que para mi sería un 360, tiene que ser ejecutable en muchos soportes, y poco a poco lo vas moldeando hasta conseguir tenerlo cerrado. (E6)

Cuando estás trabajando dentro de una agencia o tienes un briefing, a no ser que te digan específicamente que tiene que ser una acción de RR.PP., una peli, un spot específico, das opciones de muchas cosas, haces campañas que antes se llamaba 360 , ahora se le llama "plataformas", donde todas esas ideas caben. El León de Cannes que ganamos en Bungalow era una acción de RR.PP. (E9) 
Si una buena idea está muy bien adaptada a tu formato, al que justo necesitabas, no hace falta taladrar a todo el mundo con todos los medios o los canales: elige bien el canal donde tienes que contar la idea. También una gran estrategia ayuda mucho a contar la idea, hay ideas que muchas veces son estrategias. También a veces una idea de RR.PP. tiene unas características muy distintas a las que tiene un spot de ATL pero, sobre todo, es buena idea adaptada a esa categoría. (E5)

Cada medio requiere un tipo de tono diferente y la coherencia de la marca está en los valores centrales, en los conceptos y en un estilo propio.

Centrándonos en las posibilidades formales de innovación, Burtenshaw, Mahon y Barfoot (2007) aplican el concepto de simplicidad a la transmisión del mensaje a través del layout como parte del trabajo del director de arte. Fallon y Senn (2007) sitúan al mismo nivel el concepto y el aspecto formal, considerando que una ejecución brillante sin una estrategia brillante no sirve de nada, pero que una estrategia brillante sin una ejecución brillante, acaba siendo invisible (2007:11). Hernández concibe la ejecución como un recurso para atraer al público (2004: 240), e indica que el mensaje debe resultar estético, atractivo y seductor. Para Fanjul y González (2012) en la elaboración de las piezas radican los aspectos que pueden hacer al producto o servicio distinto de la competencia y que generen personalidad y notoriedad de marca. Por su parte, autores como Arroyo (2006) o Segarra (2013) advierten de que la evolución de la tecnología puede derivar en que algunas campañas sean "todo producción", priorizando lo ejecucional y dejando de lado la creatividad en el concepto y la estrategia. Esta forma de proceder es lo que en la jerga profesional se denomina "fuegos artificiales", en referencia a una creatividad mediocre que da más importancia a la espectacularidad que al contenido.

Conforme a lo expuesto, las subdimensiones vinculadas a la dimensión ejecución, son (1) la innovación en el medio y/o soporte, entendida como la parte de la propuesta creativa que se encarga de la forma de ejecutar y/o integrar la idea en el formato; (2) la adaptación de la idea al soporte y (3) la ejecución formal, propia de la dirección de arte.

\subsubsection{Adecuación al momento y al lugar}

La adecuación al momento y al lugar se plantea como dimensión transversal por estar vinculada a las 4 dimensiones principales. En lo relativo a originalidad y eficacia, el contexto actúa como escenario de difusión pero también de ideación, convirtiendo el "dónde" y el "cuándo" en variables determinantes en la búsqueda de innovación, tendencia social y viralidad (Sivera, 2014). En cuanto al engagement, Hubbard (2018) expone que un valor fundamental para lograr el gancho ("hook") consiste en impactar en el momento justo y en el lugar correcto. Algunos autores (Rayport, 2013; Nesamoney, 2015; Selva y Caro, 2016) destacan recursos para potenciar la conexión que tienen que ver con la incorporación de información contextual en tiempo real, como la adaptación del anuncio a la temperatura de la ciudad desde la que el usuario está conectado, la incorporación de la música que ha escuchado recientemente o la aparición de un contenido que le interese. Otras estrategias entrañan propuestas de valor social, como el caso de ciertas marcas que ofrecen respuestas, a través de sus campañas, a tensiones culturales y preocupaciones sociales, favoreciendo así encuentros entre emisor y receptor que den lugar a metahistorias compartidas con unos consumidores que aportarán valor de marca, generarán contenido y crearán comunidades (De Miguel y Toledano, 2018: 215). 
[...] de las tendencias actuales me gusta la potencialidad de crear productos y proyectos que apunten a productos y servicios en sí mismos. Y también me gusta que ahora las empresas quieren incorporar a sus marcas este win- win, esta intención de mejorar el planeta, de mejorar el entorno, de generar un bien común, que la razón de ser de las compañías no es generar un producto en sí sino mejorar la vida de las personas. (E1)

En lo que respecta a la ejecución, la innovación en el medio debe superar lo cotidiano y ejecutarlo en el soporte, momento y lugar adecuados, siendo este un factor determinante en la efectividad de la campaña (Ansari y Riasi, 2016). Este planteamiento fue expresado por el 55,5\% de los profesionales entrevistados y el $65 \%$ de los participantes en el estudio realizado por Stuhlfaut y Yun (2011), que destacan que los mensajes publicitarios deben presentarse en el momento y lugar correctos para resonar y conectarse con el consumidor. En ocasiones, la ubicación depende del lugar donde los consumidores buscan la información o de qué tipo de medios están utilizando. No se trata de cuántos impactos ve un consumidor, sino de la conexión que puede hacer tras una exposición, siendo esto parte de la idea creativa.

Se considera, por tanto, que la adecuación al momento y lugar representa una característica transversal implicada en (1) la innovación en el concepto (originalidad), (2) la adecuación al contexto (eficacia), (3) el impacto, entendido como gancho o atención (engagement), y la (4) innovación en el medio (ejecución).

\subsubsection{El modelo}

En base a lo estudiado, se propone un modelo que contempla cuatro dimensiones y 14 subdimensiones. Las dimensiones indican lo que los profesionales creativos valoran como indicadores de la calidad creativa y las subdimensiones expresan las características que contribuyen a desarrollar cada dimensión. La Figura 1 refleja el modelo planteado para la evaluación de la calidad creativa de una campaña de comunicación integrada. 
Fig. 1. Modelo propuesto para la evaluación de la creatividad de campañas de comunicación integrada

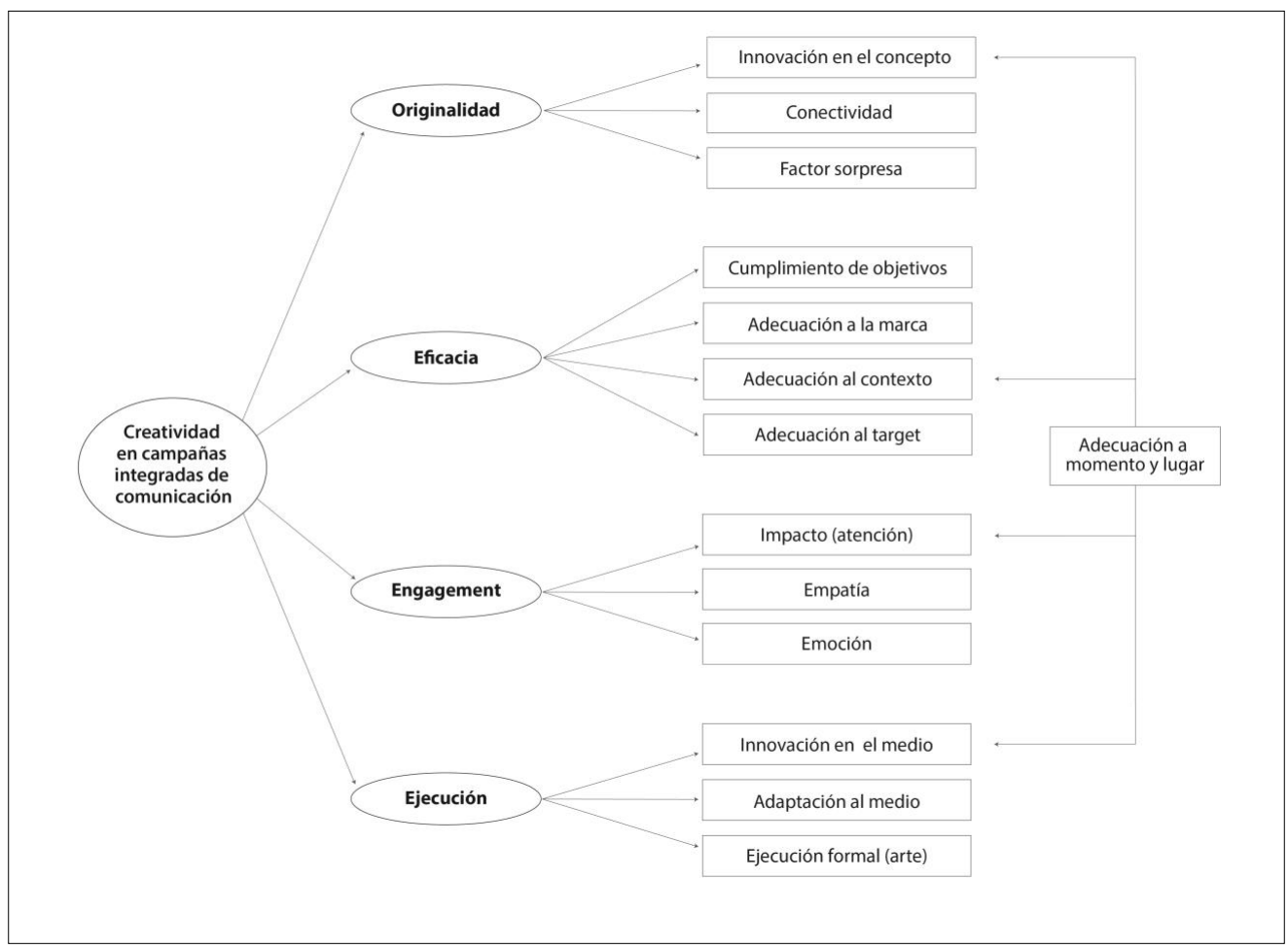

Fuente: elaboración propia

\section{Discusión y conclusiones}

En el entorno profesional la evaluación de la creatividad está guiada por conocimientos implícitos o marcos teóricos informales (Kover, 1995), adquiridos a través de la experiencia, que son difíciles de transferir entre individuos y que derivan en valoraciones caracterizadas por la indefinición y la subjetividad. Esta situación se reproduce en las asignaturas relacionadas con creatividad publicitaria y en las RR.PP. enmarcadas en los grados en Publicidad y RR.PP. cuando tratan de emular en el aula la práctica profesional (Gil, 2012). En el escenario docente, la ausencia de sistematización en la evaluación presenta dos grandes dificultades respecto al sector profesional: por un lado, es necesario traducir la evaluación cualitativa a una calificación numérica que la represente y que sea comprendida por los estudiantes; por otro, los estudiantes necesitan recursos para desarrollar el juicio crítico y poder filtrar y optimizar sus propuestas creativas con cierta autonomía, lo que se traduciría en un dominio mínimo de la materia. Las investigaciones en torno a la brecha académi- 
co-profesional revelan que la capacitación de los discentes no se adecua a los requerimientos actuales de una industria (Corredor y Farfán, 2010) cuyas características incrementan la complejidad en la evaluación creativa. En la era de la Comunicación Persuasiva Integrada (Castelló y del Pino, 2019), la búsqueda de relevancia social y la integración de públicos y canales han quebrado las barreras que separaban comunicación, producto y entretenimiento, haciendo que Publicidad y RR.PP. converjan en campañas de comunicación integrada caracterizadas por la búsqueda de earned media y por una creatividad líquida que contempla el empleo de los medios como parte de la solución creativa. El escenario integrado y la ausencia de patrones en el uso de los medios incrementan la dificultad para identificar y verbalizar las dimensiones en base a las que formar y evaluar a los estudiantes.

El objetivo de esta investigación es identificar las dimensiones implícitas en la evaluación profesional de la creatividad para desarrollar un recurso que permita a los alumnos de los grado en Publicidad y Relaciones Públicas asimilar criterios que contribuyan a evaluar la creatividad de campañas de comunicación integrada. El presente estudio es pionero en España en identificar, a partir de una extensa revisión de la literatura y de declaraciones procedentes de profesionales creativos, las dimensiones de evaluación de la calidad creativa en las campañas de comunicación integrada. Los resultados muestran que las teorías implícitas utilizadas por los profesionales se alinean con las teorías o modelos de los académicos. No obstante, la academia emplea términos que no se verbalizan o que resultan ambiguos en la realidad laboral (Hubbard, 2018).

El modelo que aquí se propone podría resultar útil para eliminar ambigüedades en la interpretación de los conceptos durante las distintas fases del proceso creativo, pudiendo contribuir a verbalizar de forma uniforme las fortalezas y debilidades de las alternativas creativas durante la argumentación en la agencia y con el cliente. No obstante, se considera que la mayor aportación del presente estudio se remite al entorno docente, donde contar con indicadores o dimensiones de referencia contribuiría a evaluar y guiar el trabajo creativo de los estudiantes, así como a desarrollar, a medio plazo, un dominio mínimo sobre la materia mediante la integración, a través de la práctica, de las dimensiones propuestas en el modelo.

La ausencia de identificación por parte del sector profesional de las dimensiones implícitas en la evaluación de la creatividad ha dado lugar a estudios que, desde la academia y en la línea del nuestro, han intentado identificar, categorizar y traducir dicho proceso a términos operativos. Cabe destacar el estudio de Tur (2018), que a partir de una revisión de la literatura propone una batería de preguntas para valorar el producto creativo en el contexto docente y evaluar a los estudiantes en las materias creativas desde una perspectiva basada en el análisis y la experimentación. Aunque varias dimensiones han aparecido bajo otros formatos en estudios anteriores, el modelo que presentamos entraña novedades tanto en su contenido como en su finalidad. En lo que respecta al contenido cabe señalar que: a) ningún otro modelo introduce el engagement como dimensión que aglutina atención, empatía y emoción; b) ninguno contempla la dimensión ejecución desde una perspectiva dual en lo referido a innovación en medios y aspecto formal; c) es el primer modelo que presenta la adecuación al momento y al lugar como característica transversal.

En cuanto a su finalidad, la aportación diferencial es que el modelo está diseñado ad hoc para ser implementado en la evaluación de campañas de comunicación integrada. Mientras algunos modelos anteriores presentan un enfoque de- 
masiado genérico (Smith, Chen y Yang, 2008; Caroff y Besançon, 2008) o demasiado específico (Koslow, Sasser y Riordan, 2003, 2006; Horn y Salvendy; 2006, 2009) -dimensiones como “síntesis" podrían ser adecuadas para la evaluación de gráficas publicitarias, de igual modo que la "integración de los valores corporativos" podría llegar a ser una dimensión relevante si hablásemos de la evaluación de eventos- dadas las características heterogéneas de las campañas de comunicación integrada, cuya creatividad trasciende el concepto para innovar en el medio, es necesario aplicar una mirada holística que abarque la evaluación en varios medios y soportes sin perder la visión de conjunto hacia el objetivo de la campaña. De ahí que el modelo se haya construido teniendo en cuenta este escenario y la posibilidad de evaluar campañas de diversa índole, desde las enfocadas a generar comunidad a través de acciones de experiencia a aquellas otras que, apoyadas en un insight temporal y reforzadas por la producción gráfica y audiovisual, pretendan cambiar una actitud del público o romper un freno social. De modo que el patrón común en la evaluación de las campañas de comunicación integrada sea que respondan a las dimensiones de eficacia, originalidad, engagement y ejecución. Esto no quiere decir que estas dimensiones sean las únicas o que toda la comunicación deba guiarse por ellas, sino que el modelo proporciona un referente con el que evaluar o filtrar las campañas de comunicación integrada durante el proceso creativo. Siendo la comunicación persuasiva integrada altamente creativa la que alcanzaría la máxima gradación en cada una de las dimensiones.

Como futuros desarrollos de la investigación se plantea el diseño, a partir del modelo propuesto, de una herramienta adaptada a los estudiantes del Grado en Publicidad y RR.PP. que suponga un instrumento formativo que los guíe en las etapas conceptuales del proceso creativo en el aula y contribuya a sistematizar la evaluación, reduciendo la subjetividad y haciendo comprensible la evaluación docente.

\section{Referencias bibliográficas}

Aguilera, R. (2017). Análisis de los modelos que evalúan la creatividad en los productos publicitarios (tesis doctoral). Barcelona: Universidad Autónoma de Barcelona. Recuperado de: https://cutt.ly/PtMtSwa

Ang, S. y Low, S. (2000). "Exploring the dimensions of ad creativity", Psychol. Mark. 17, 835-854. https://cutt.ly/xtMkL4Q

Altarriba, M. y Rom, J. (2008). (Re)formar a los creativos. ¿Las campañas son un reflejo de las demandas actuales de la profesión?. IV Simposium de Profesores Universitarios de Creatividad. Pamplona: Universidad de Navarra. Recuperado de: https://cutt.ly/MtZCpse

Amabile, T. (1983). The Social Psychology of Creativity. New York: Springer-Verlag.

Ansari, A. y Riasi, A. (2016). An Investigation of Factors Affecting Brand Advertising Success and Effectiveness. International Business Research, 9 (4), 20. Recuperado de: https://cutt.ly/ttZCaCn

Arroyo, I. (2006). La profesión de crear. Creatividad e Investigación publicitarias. Madrid: Ediciones del Laberinto.

Baños, M. y Ramírez, J. (2004). Una nueva creatividad publicitaria para las nuevas fórmulas de comunicación comercial. Creatividad y sociedad, 6, 17-26. Recuperado de: https://cutt.ly/otZCEk4

Barahona, N. (2019). Creatividad Publicitaria, ¿cómo juzgarla?. Barcelona: UOC. 
Bartolomé, A.; Viñarás, M. y Llorente, C. (2012). Emprendedores y creativos: una propuesta interdisciplinar de innovación docente. Vivat Academia, 117, 1613-1641. Recuperado de: https://cutt.ly/GtV4niW

Bartolomé, A.; Llorente, C. y Marugán, F. (2018). Telepizza y Universidad CEU San Pablo. Adquisición de competencias transversales en área de creatividad publicitaria. En González, M. Valderrama, M. (coords.). Discursos comunicativos persuasivos hoy, 31- 43. Madrid: Tecnos.

Bassat, L. (1993). El libro rojo de la publicidad. Ideas que mueven montañas. Barcelona: Folio.

Besemer, S. y O'Quin, K. (1989). The development, reliability, and validity of the revised Creative Product Semantic Scale. Creativity Research Journal. 2 (4), 267-278. Recuperado de: https://cutt.ly/ZtZCYf5

Besemer, S. y Treffinger, D. (1981). Analysis of creative products. Review and synthesis. Journal of Creative Behavior, 15 (3), 158-178. Recuperado de: https://cutt.ly/TtZCI6Q

Burtenshaw, C., Mahon, K. y Barfoot, C. (2007). Principios de publicidad. El proceso creativo: agencias, campañas, medios, ideas y dirección de arte. Barcelona: Gustavo Gili.

Caroff, X. y Besançon, M. (2008). Variability of creativity judgments. Learning and Individual Differences, 18 (4), 367-371. Recuperado de: https://cutt.ly/jtZCAsd

Carretero, M. y Rangel, C. (2017). Comunicación estratégica integral frente a publicidad tradicional. aDResearch: Revista Internacional de Investigación en Comunicación, 15 (15), 32-53. Recuperado de: https:/ / cutt.ly/YtZCSF3

Castelló, A. y Del Pino, C. (2019). De la publicidad a la comunicación persuasiva integrada: estrategia y empatía. Madrid: ESIC.

Cook, R. (2002). Thoughts on Skills for Tomorrow's Media. Journal of Media Practice, 2, (3), 186- 188. Recuperado de: https://cutt.ly/atZCZkR

Corredor, P. y Farfán, J. (2010). Demandas y formación: Nuevos perfiles profesionales para la Publicidad en España. Pensar la Publicidad. Revista internacional de investigaciones publicitarias, 4, (1), 97-116. Recuperado de: https://cutt.ly/ ctZCXU7

De Miguel, Z. y Toledano F. (2018). Storytelling y storydoing: técnicas narrativas para la creación de experiencias publicitarias. En García, F., Tur-Viñes, V., Arroyo, I. y Rodrigo, L. (coords.), Creatividad en publicidad. Del impacto al comparto, 215-232. Madrid: Dykinson.

Estanyol, E. y Roca, D. (2014). Creativity in PR consultancies: Perception and management, Public Relations Review. Recuperado de: https://cutt.ly/HtZCCWA

Fallon, P. y Senn, F. (2007). Exprime la idea. Madrid: Lid Editorial.

Fanjul, C. y González, C. (2012). El rol de los códigos verbales de la realidad en la creatividad del discurso publicitario. Doxa Comunicación, 14, 75-97. Recuperado de: https://cutt.ly/5tZCVwA

Glaser, B. (1978). Theoretical sensitivity. Mill Valley. California: Sociology Press.

Glaser, B. (1992). Basics of grounded theory analysis: Emerge vs. Forcing. Mill Valley. California: Sociology Press. 
Glaser, B. y Strauss, A. (1967). The Discovery of Grounded Theory: strategies for qualitative research. New York: Aldine.

Gil, N. (2012). La evaluación de la creatividad publicitaria en el ámbito docente (tesis doctoral). Barcelona: Universitat Pompeu Fabra. Recuperado de: https://cutt.ly/ytZCVIq

Goldhaber MH. 1997. The attention economy and the Net. First Monday

Guilford, P. (1950). Creativity. American Psychologist, 5 (9), 444-454. Washington: American Psychological Association. Recuperado de: https://cutt.ly/BtZC1G0

Halper, F. (2013). Predictive Analytics for Business Advantage. TDWI Research. Recuperado de: https://cutt.ly/ktZCOhz Hernández, C. (2004). Manual de creatividad publicitaria. Madrid: Síntesis.

Horn, D. y Salvendy, G. (2006). Product Creativity: Conceptual Model, Measurement and Characteristics. Theoretical Issues in Ergonomics Science, 7 (4), 395-412. Recuperado de: https://cutt.ly/VtZC2KF

Horn, D. y Salvendy, G. (2009). Measuring Consumer Perception of Product Creativity: Impact on Satisfaction and Purchasability. Human Factors and Ergonomics in Manufacturing, 19 (3), 223-240. Recuperado de: https://cutt.ly/ptZC91R

Hubbard, K. (2018). The Academic-Practitioner Gap ... Is It as Vast as It Sounds?: A Creative Perspective. Journal of current issues \& research in advertising, 39 (3), 272-288. Recuperado de: https://cutt.ly/htZC3EO

Jackson, N. (2005). Assessing creativity: synthesis of teachers' views. The Higher Education Academy, Heslington. Recuperado de: https://cutt.ly/TtZC8v9

Kleeba, J. y Tierney, P. (2012). Advertising Creativity: A review and empirical investigation of external evaluation, cognitive style and self-perception of creativity. Journal of Current Issues and Research in Advertising, 17 (2), 33-52. Recuperado de: https://cutt.ly/DtZC4h2

Koslow, S., Sasser, S. L. y Riordan, E. A. (2003). What Is Creative to Whom and Why? Originality, Strategy and Artistry Perceptions in Advertising Agencies. Journal of Advertising Research, 43 (1), 96-110. Recuperado de: https://cutt.ly/ptZVr6u

Koslow, S., Sasser, S. L. y Riordan, E. A. (2006). Do Marketers Get the Advertising They Need or the Advertising They Deserve?. Journal of Advertising, 35 (3) 81-101. Recuperado de: https://cutt.ly/RtZVtC7

Kover, A. (1995). Copywriters' Implicit Theories of Communication: An Exploration. Journal of Consumer Research, 21 (4), 30-45. Recuperado de: https://cutt.ly/atZVu5u

López de Ayala, M.C. (2004). El análisis sociológico del consumo: una revisión histórica. Sociológica: Revista de pensamiento social, 5: 161 - 190. Recuperado de: https://cutt.ly/LtZVinz

Navarro, C. (2007): Creatividad publicitaria eficaz. Madrid: ESIC.

Nesamoney, D. (2015). Personalized digital advertising: How data and technology are transforming how we market. Old Tappan: Pearson Education.

Obradors, M. (2007). Creatividad y generación de ideas: estudio de la práctica creativa en el cine y en la publicidad. Barcelona: Aldea Global. 
Plucker, A., Beghetto, A. y Dow, T. (2004). Why isn't creativity more important to educational psychologists? Potentials, pitfalls, and future directions in creativity research. Educational Psychologist, 39(2), 83-96. Recuperado de: https://cutt. ly/PtZVi5M

Rayport, F. (2013). Advertising's new medium: human experience. Harvard business review, 91 (3), 76-82. Recuperado de: https://cutt.ly/dtZVogl

Ross, M. (1989). Relation of Implicit Theories to the Construction of Personal Histories. Psychological Review 96 (2):341. Recuperado de: https://cutt.ly/xtZVoO1

Ricarte, J. (1999). Creatividad y comunicación persuasiva. Barcelona: Aldea Global.

Runco, M. y Charles. R. (1993). Judgments of originality and appropriateness as predictors ofcreativity. Personality and Individual Differences, 15, (5), 537-46. Recuperado de: https://cutt.ly/ctZVpol

San Martín, D. 2014. Teoría fundamentada y ATLAS.ti: recursos metodológicos para la investigación educativa. Revista electrónica de investigación educativa 16(1): 104-122. Recuperado de: https://cutt.ly/dtBRAlE

Sarkar, P. y Chakrabarti, A. (2011). Assessing design creativity. Design Studies.32 (4), 348-383. Recuperado de: https://cutt. ly/BtZVp6q

Segarra, T. (2013). Creatividad en un mundo complejo, Conferencias El Sol. Recuperado de: https://cutt.ly/NtZVstw

Selva, D. y Caro, L. (2016). Uso de datos en creatividad publicitaria: el caso de Art, Copy \& Code de Google. El profesional de la información, 25 (4), 642-651. Recuperado de: https://cutt.ly/JtZVdtG

Smith, E., Mackenzie, B., Yang, X., Buchholz, M. y Darley K. (2007). Modeling the Determinants and Effects of Creativity in Advertising, Markting Science, 26, 819- 833. Recuperado de: https://cutt.ly/ttZVfw8

Smith, Robert E., Chen, J. y Yang, X. (2008). The Impact of Advertising Creativity on the Hierarchy Effects. Journal of Advertising, 37, 47-61. Recuperado de: https://cutt.ly/gtZVfAk

Sivera, S. (2014). Marketing viral: claves creativas de la viralidad publicitaria (tesis doctoral). Barcelona: Universitat Ramón Llul. Recuperado de: https://cutt.ly/ZtN8YPq

Solana, D. (2010). Postpublicidad: reflexiones sobre una nueva cultura publicitaria. Barcelona: Doubleyou.

Soneira, A. J. 2006. La teoría fundamentada en los datos (grounded theory) de Glaser y Strauss, pp. 153-173. En: I. Vasilachis. Estrategias de investigación cualitativa. Barcelona: Gedisa.

Stuhlfaut, M. (2011). The creative code: An organizational influence on the creative process in advertising. International Journal of Advertising, 30 (2):283. Recuperado de: https://cutt.ly/PtZVgOi

Stuhlfaut, M. y Yun, C. (2011). A tool for evaluating advertising concepts: desirable characteristics as viewed by creative practitioners. Journal of Marketing Communications, 19:2, 81-97. Recuperado de: https://cutt.ly/FtZVg1I

Taylor, A. y Sandler, E. (1972). Use of Creative Product Inventory for evaluating products of chemists. Proceedings of the 80th Annual Convention of the American Psychological Association. 7 (1), 311-312. Recuperado de: https://cutt.ly/vtZVlIi 
Taylor C.R., Wilson R.D., y Miracle W. L. (1994). The Impact of Brand Differentiating Messages on the Effectiveness of Korean Advertising. Journal of International Marketing, 2 (4) 31-52. https://cutt.ly/ItMjpVg

The Holmes Report, Ketchum y Now-Go-Create (2013). Creativity in PR: A global study. Recuperado de: https://cutt.ly/ rtZVvux

Torrance, P. (1977). Creativity in the classroom. What research says to the teacher. Washington: National Education Association.

Treffinger, J. (1980). Encouraging creative learning for the gifted and talented. Ventura: Country Superintendent for Schools. Tucker, C. (2014). Social networks, personalized advertising and privacy controls. Journal of marketing research, 51 (5), 546-562. Recuperado de: https://cutt.ly/jtZVbeZ

Twose, D. y Polly, W. (2011). Creative effectiveness. Millward Brown. Recuperado de: https://cutt.ly/stZVbLw

Van Doorn, J., Lemon, K. N., Mittal, V., Nass, S., Pick D., Pirner, P. y Verhoef, P. (2010). Customer engagement behavior: Theoretical foundations and research Directions. Journal of Service Research, 13, 253. Recuperado de: https://cutt.ly/ ctZVmiw

Vejling, L., Tomba, C. y Mateo, A. (2014). La esencia creativa de la publicidad. Mendoza: Editorial UMaza. Recuperado de: https://cutt.ly/YtZVEwD

White, A. y Smith, L. (2001). Assessing advertising creativity using the Creative Product Semantic Scale, Journal of Advertising Research.41, (6), 27-35. Recuperado de: https://cutt.ly/ttZVmXg

West, C., Caruana, A. y Leelapanyalert K. (2013). What makes win, place or show? Judging Creativity in Advertising at Award Shows. Journal of Advertising Research, 53 (3), 324-338. recuperado de: https://cutt.ly/VtZVQUk 


\section{Anexos}

\subsection{Guía de entrevistas}

\section{Datos previos del ENTREVISTADO}

1. Nombre

2. Año de nacimiento

3. ¿Cuál es tu formación académica? / ¿Cómo te formaste en creatividad publicitaria?

4. ¿Cuál es tu opinión sobre lo que aprendiste de creatividad publicitaria en la licenciatura/máster?

- ¿Estás satisfecho/a con la formación que recibiste?

5. ¿Cuántos años has trabajado en publicidad?

6. ¿Para cuántas agencias has trabajado y en qué puesto/perfil?

7. ¿Cuál es tu puesto de trabajo actual? / ¿Cuánto tiempo llevas en tu trabajo actual?

8. ¿Qué otros puestos de trabajo has desempeñado en publicidad?

9. ¿ ¿Has trabajado como creativo en RR.PP? / ¿Has trabajado las creatividad en RR.PP. como parte de alguna campañas de publicidad?

10. ¿Has sido freelance?

11. ¿ Has sido docente? $>$ (¿Dónde?) $>$ ¿Cómo fue tu experiencia?

12. ¿Has sido jurado en algún festival de publicidad? > (¿Dónde?) > ¿Cómo fue tu experiencia?

\section{Opiniones sobre el SECTOR}

Me gustaría empezar conociendo tu opinión sobre el sector de la publicidad ...

1. En términos generales, ¿qué dirías que caracteriza la publicidad hoy en día?

2. ¿Cómo ha cambiado la industria de la publicidad desde que empezaste?

3. Según tu opinión, ante la era digital, ¿cómo influyen los medios digitales en la forma de hacer publicidad?

4. ¿Cuál consideras que es el papel de la creatividad en publicidad?

\section{RECONOCER la idea}

Pasamos a algunas preguntas que tienen que ver con la identificación de la idea creativa...

1. ¿Qué tiene que tener una buena campaña de publicidad? / si tuvieras que decir qué factores indican la calidad creativa de una campaña, ¿con cuáles te quedarías?

2. ¿Qué papel juegan la creatividad y la eficacia para determinar lo que es una buena campaña? 
3. A la hora de validar una idea o una campaña creativa a nivel interno, ¿qué criterios empleáis para evaluarlas? / ¿qué tienen estas buenas ideas o campañas?

4. ¿Cómo dirías que es la relación entre cuentas, creatividad y planificación en torno a la creación de la idea y a su aprobación?

5. ¿Cómo crees que tus clientes valoran la creatividad?

6. Me gustaría saber tu opinión sobre las diferencias entre lo que es una buena campaña para la agencia y para un festival.

7. Cuando has sido jurado en premios de creatividad, ise sigue un criterio?

8. Identificamos que la web del festival de Cannes no indica un criterio unificado para la evaluación... [la web] indica que se valora por un lado originalidad, por otro creatividad... ¿ Cómo interpretas esta diferencia entre originalidad y creatividad?

\section{CREAR la idea}

Pasamos a algunas preguntas que tienen que ver con la generación de la idea creativa...

Hemos hablado sobre el sector y sobre cómo reconocer una idea creativa, me gustaría que habláramos sobre la estrategia que usas para generar la idea ...

1. ¿Cómo se generan las ideas?

2. ¿Alguna vez has utilizado técnicas de generación de ideas?

3. ¿Qué papel juega el equipo en el proceso creativo?

4. ¿Cómo es la estructura de tu departamento creativo?

5. ¿Qué es lo que más ha influido en la forma en que haces tu trabajo?

\section{Preguntas de CIERRE}

1. ¿Qué crees que es lo más importante que los estudiantes en creatividad publicitaria deberían estar aprendiendo?

$$
\text { a. ¿Por qué? }
$$

2. ¿ ¿Hay algo que olvidé preguntar que crees que puede ser útil?

3. ¿Alguna idea final sobre tus experiencias en publicidad?

¡Muchas gracias por tu colaboración! 